\title{
CARACTERIZAÇÃO DE ARGAMASSAS HISTÓRICAS: ESTUDO DE CASO DO MERCADO PÚBLICO DE JARDIM DE PIRANHAS/RN
} CHARACTERIZATION OF HISTORICAL MORTARS: CASE STUDY OF THE PIRANHAS / RN PUBLIC GARDEN MARKET

\author{
SALUSTIO, JANAINA \\ Professora \\ Universidade Federal Rural do Semi-Árido \\ Rio Grande do Norte; Brasil \\ janaina.salustio@ufersa.edu.com
}

\author{
ALMEIDA, JOSÉ \\ Engenheiro Civíl \\ Universidade Federal Rural do Semi-Árido \\ Rio Grande do Norte; Brasil \\ josecarloss_gomes@hotmail.com
}

\author{
BARROS, JOMÁRIO \\ Graduando em Engenharia Civil \\ Universidade Federal Rural do Semi-Árido \\ Rio Grande do Norte; Brasil \\ jomario108@hotmail.com \\ SOBRAL, TEREZA \\ Graduando em Engenharia Civíl \\ Universidade Federal Rural do Semi-Árido \\ Rio Grande do Norte; Brasil \\ tete-olivia@hotmail.com
}

\section{RESUMO}

Ao longo dos anos as edificações acabam por sofrerem danos que, quando não são sanados corretamente, pode levar à edificação a ruína, apagando assim parte da história de um povo, especialmente em edificações históricas. Em se tratando desse tipo de edificação, é imprescindível a utilização dos materiais adequados, para sua correta preservação. Dessa maneira, se faz necessário o conhecimento acerca das características dos materiais empregados na época da construção com a finalidade de tentar utilizar-se de materiais semelhantes aos que foram inicialmente empregados. Nesse sentido, o presente trabalho tem por objetivo a caracterização da argamassa de uma edificação histórica obtendo informações acerca dos materiais empregados em seu preparo, bem como análises que fundamentem o entendimento de suas características. A edificação analisada consiste de um mercado público localizado na cidade de Jardim de Piranhas/RN datada de 1951. Para atender aos objetivos, foram realizados ensaios de ataque ácido, análise granulométrica e taxa de absorção. Os resultados alcançados mostraram que os traços utilizados não eram diferenciados em razão de estar em ambiente interno ou externo, as proporções de agregado miúdo usados na argamassa bem como sua taxa de absorção foram altas.

Palavras-chave: Construções antigas. Revestimentos. Argamassa de cal. Intervenções. Métodos de caracterização.

\section{ABSTRACT}

Over the years buildings end up suffering damage that, when not properly remedied, can lead to building ruin, thus erasing part of a people's history, especially in historic buildings. When it comes to this type of building, it is essential to use the appropriate materials for their correct preservation. Thus, it is necessary to know about the characteristics of materials used at the time of construction in order to try to use materials similar to those initially used. In this sense, the present work aims to characterize the mortar of a historic building obtaining information about the materials used in its preparation, as well as analyzes that support the understanding of their characteristics. The analyzed building consists of a public market located in the city of Jardim de Piranhas / RN dating from 1951. To meet the objectives, acid attack tests, particle size analysis and absorption rate were performed. The results showed that the traits used were not different due to being indoors or outdoors, the proportions of fine aggregate used in the mortar as well as its absorption rate were high.

Keywords: Old Buildings. Coatings. Lime mortar. Interventions Characterization Methods

\section{INTRODUÇÃO}

As edificações históricas retratam o passado da sociedade. por meio delas é possível compreender a importância de determinada cidade ou região. Entretanto, com o passar do tempo, muitas cidades acabam por perder edificações construídas, edificações essas compostas com traços arquitetônicos que remontam a sua época de construção, o que pode ser considerado um crime a memória arquitetônica da cidade. (RODRIGUES, 2013). 
Com o passar do tempo, e o consequente envelhecimento da estrutura, há necessidade de cada vez mais intervenções visando sanar manifestações patológicas nas edificações e preservar assim sua integridade. Um dos componentes mais afetados nas intervenções feitas em prédios históricos é a argamassa de revestimento, a qual é substituída em sua maioria por materiais a base de cimento, o que faz com que o revestimento obtenha propriedades diferentes do revestimento original, prejudicando assim a maneira de trabalhar do conjunto alvenaria/revestimento, trazendo graves problemas a edificação (KANAN, 2008).

Com a finalidade de preservar os patrimônios históricos, restaurando tais edificações e garantindo a preservação de sua originalidade surge a ideia de caracterização dos materiais utilizados na construção da edificação. A caracterização de materiais, em especial da argamassa, tem por finalidade o estudo e análise dos insumos empregados na produção da argamassa, tentando assim fazer uma reconstituição do seu traço, para que o mesmo seja refeito em uma eventual intervenção na edificação, e para que a mesma continue com materiais semelhantes aos utilizados à sua época de construção (RODRIGUES, 2013).

As argamassas de edificações históricas, desempenham funções importantes como por exemplo, a de revestimento, sendo responsável por conferir proteção a alvenaria contra a ação de agentes agressivos como a chuva e o sol. Em razão disso, se faz necessário desenvolver argamassas de reparo com características semelhantes as originalmente empregadas, mas para isso, se faz necessário primeiro, identificar as principais características da argamassa inicialmente utilizada. Intervenções com materiais totalmente diferentes dos empregados à época de sua construção, pode fazer com que ocorra uma mudança no modo de trabalho dos componentes da edificação (SANTOS E VEIGA, 2012).

\section{PROCEDIMENTO}

\subsection{Procedimento experimental}

Objetivando realizar a caracterização de argamassas históricas procurou-se encontrar uma edificação que atendesse as exigências desse tipo de trabalho. Decidiu-se então verificar o prédio na qual funciona o Mercado Público da cidade de Jardim de Piranhas/RN. Inicialmente foi feita uma análise histórica da edificação, buscando assim conhecer o ano em que a mesma foi construída e se a mesma enquadrava-se na proposição do referido tema objeto deste trabalho. Logo após foi feita uma visita in loco.

A partir disso, sucedeu-se a coleta das amostras, obedecendo aos critérios existentes, como por exemplo, realizar a extração com 1,5 a 2 metros de altura do piso. Depois de coletadas, as amostras foram identificadas de acordo com o local de extração para então seguirem ao laboratório. O laboratório utilizado para a realização dos ensaios foi o laboratório de materiais de construção civil da UFERSA - Campus Angicos/RN, na qual as amostras foram preparadas e, por meio das técnicas de caracterização, buscou-se atingir o objetivo de realizar a caracterização das argamassas, conhecendo assim a sua composição, bem como presumindo seu comportamento, afim de que em possíveis intervenções possam ser empregados materiais de características semelhantes ao original.

Como técnicas de laboratório foram escolhidas usar os ensaios de granulometria, norteado pela NBR NM 248/03 Agregados - determinação da composição granulométrica, e ensaio de absorção, orientado por meio da nbr 9778/05 Argamassa e concreto endurecidos - determinação da absorção de água índice de vazios e massa específica, e também foi utilizada a técnica de ataque ácido, realizada com a adição de ácido clorídrico (HCL) em amostras do revestimento.

\subsection{Analise histórica da edificação}

O Mercado Público possuía $824 \mathrm{~m}^{2}$ de área construída e era inicialmente composto por 18 salas, 2 banheiros e uma área ao centro do mesmo destinada para circulação de pessoas que por ali passavam. Já que funcionavam restaurantes e lanchonetes em algumas de suas salas, essa área central era destinada a colocação de mesas e cadeiras.

A edificação possui 67 anos de construção e foi utilizada até o ano de 2013, quando foi interditada, uma vez que se encontrava muito desgastada pelo uso e pelo tempo e, dessa maneira, oferecia riscos a integridade física de seus usuários. Ao longo de todos esses anos de utilização o Mercado nunca passou por serviços de manutenção. A Figura 1 ilustra a parte frontal da edificação em análise. 
Figura 1 - Fachada posterior

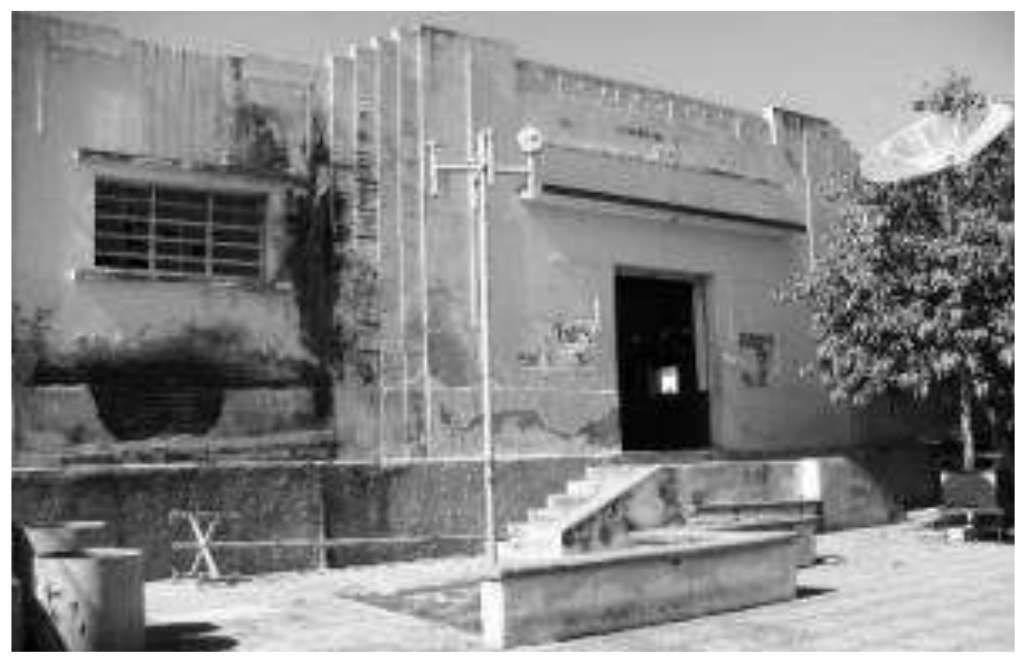

Fonte: Próprio autor (2018)

Após longos três anos de interdição, o prédio começou a passar pelo processo de reforma em 2016, tendo sido concluído em 2018. O projeto arquitetônico do novo mercado é representado na Figura 2.

Figura 2 - Projeto arquitetônico do Mercado Público.

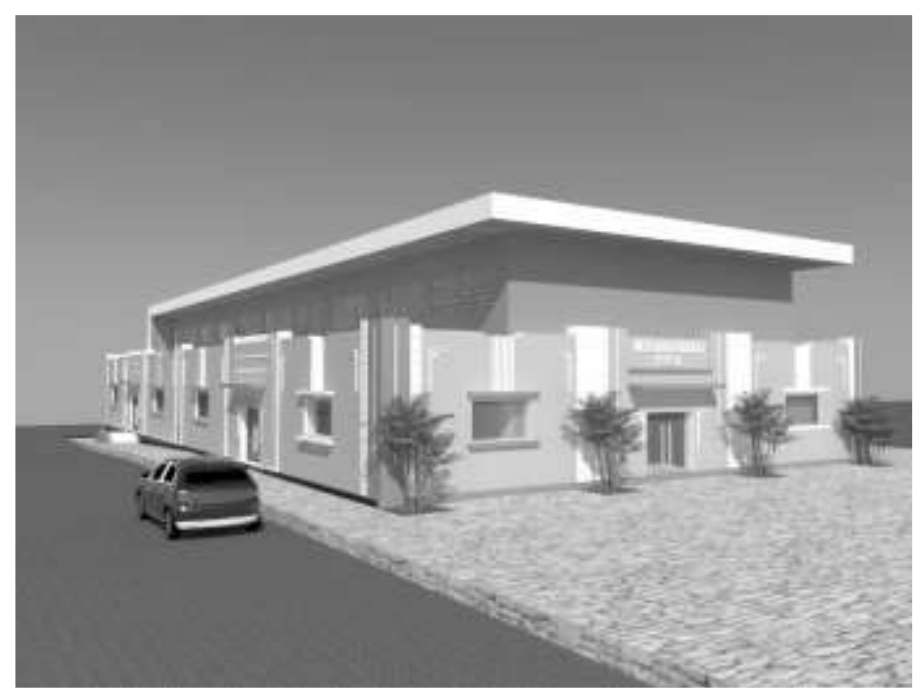

Fonte: Disponibilizado pela construtora executora do serviço de reforma (2018).

\subsection{Preparação das amostras}

Após a extração, as amostras foram encaminhadas ao laboratório, afim de que se procedesse aos ensaios necessários para ao final obter as proporções de materiais empregados na constituição do revestimento utilizado.

A preparação das amostras iniciou-se com a remoção da película de tinta existente na superfície das mesmas, $\operatorname{logo}$ seguida do maceramento, processo que consiste em fragmentar os pedaços das amostras em pedaços ainda menores, fazendo com que ocorra a sua desagregação, ou seja, a amostra era submetida a uma espécie de moagem manual.

A Figura 3 ilustra um exemplo do tamanho e condições da amostra analisada. 
Figura 3 - Amostra após ser extraída

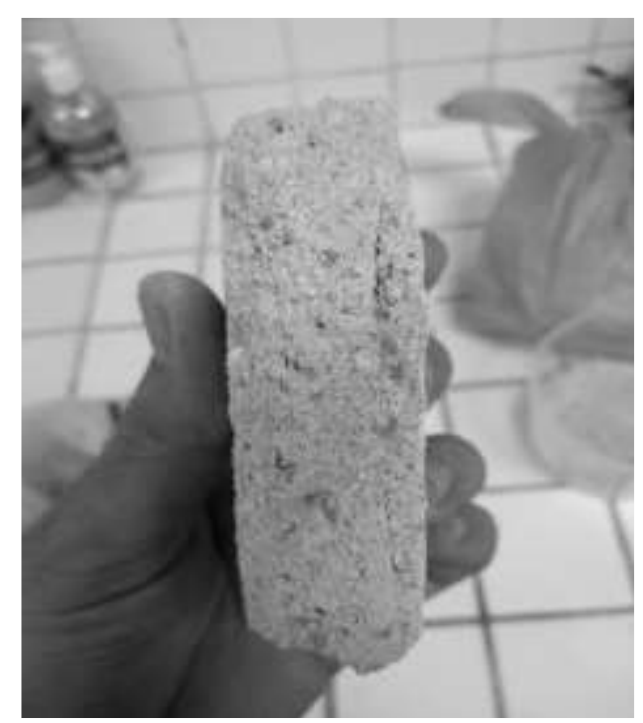

Fonte: Autoria Própria (2018).

A remoção da película de tinta foi realizada utilizando-se de espátulas de aço e colher de pedreiro. Para o maceramento foram utilizadas uma bandeja e uma marreta de borracha, afim de não danificar as partículas.

As amostras foram extraídas de diversas paredes da edificação, tanto interna quanto externa, a fim de verificar se existiam traços diferenciados em função do ambiente de exposição. O Quadro 1 trás a identificação adotada nas amostras extraídas e seu local de extração.

Quadro 1 - Legenda adotada para as amostras extraídas

\begin{tabular}{|c|c|}
\hline IDENTIFICAÇÃO DA AMOSTRA & LOCAL DE ORIGEM \\
\hline A1 & Parede interna lateral esquerda \\
\hline A2 & Parede interna posterior \\
\hline A3 & Parede interna lateral direita \\
\hline A4 & Parede interna frontal \\
\hline A5 & Parede interna lateral esquerda \\
\hline A6 & Parede externa lateral esquerda \\
\hline A7 & Parede externa posterior \\
\hline
\end{tabular}

Fonte: Autoria Própria (2018).

Após o maceramento, as amostram foram pesadas em balança digital com precisão de $0,01 \mathrm{~g}$ e logo depois seguiram para secagem na estufa por 24 horas, com temperatura variando entre 97 e $106^{\circ} \mathrm{C}$, a fim de serem preparadas para sofrerem o ataque ácido.

\subsection{Ensaios}


Os ensaios seguiram a seguinte sequência: primeiro foi realizado o ataque ácido e, após isso, com o agregado resultante do ataque foi feito o ensaio de granulometria e por fim, amostras não destorroadas foram submetidas ao ensaio de absorção.

O ataque das amostras por ácido visa provocar a degradação do aglomerante, que nesse caso é a cal, possibilitando que apenas os agregados permaneçam preservados na amostra. Tal procedimento baseia-se no fato de que o ácido clorídrico dilui o aglomerante deixando apenas o agregado insolúvel. Isso se dá em razão de que ao entrar em contato com o carbonato de cálcio, o ácido clorídrico reage causando o seu consumo e liberando, $\mathrm{CaCl}_{2} \mathrm{CO}_{2}$ e água. Devido a existência de quartzo no agregado, o mesmo fica intacto. A equação é descrita a seguir:

$$
2 \mathrm{HCL}+\mathrm{CaCO}_{3} \rightarrow \mathrm{CaCl}_{2}+\mathrm{H}_{2} \mathrm{O}+\mathrm{CO}_{2}
$$

Para realização desse procedimento foram utilizados $150 \mathrm{ml}$ de produto com ácido clorídrico a 14\% (HCL) em amostras de $100 \mathrm{~g}$ do revestimento. O ácido clorídrico foi colocado em uma proveta e adicionado à amostra, que estava em um recipiente de vidro. A partir de então, foi utilizado uma pinça de plástico para mexer o conteúdo da amostra e assim fazer com que o ácido penetrasse em todo o material.

Após sofrer o ataque ácido, as amostras passaram por um processo de filtragem em papel filtro, objetivando assim a remoção de parte do ácido. Durante o processo de filtração foi utilizado uma pisseta com água a fim de se fazer a limpeza do material que ficou na parte superior do papel filtro, fazendo com que todo material seja filtrado.

Após o processo de filtragem, as amostras retornaram a estufa por 24 horas novamente, objetivando assim a secagem por completa do material, para só então ser realizado a pesagem final e o ensaio de granulometria

\section{RESULTADOS}

\subsection{Ataque acido}

A Tabela 1 mostra a relação entre aglomerante e agregado obtida em massa através do ataque ácido, bem como o traço equivalente estimado.

Tabela 1 - Relação em massa aglomerante agregado e traço estimado.

\begin{tabular}{c|c|c|c|c}
\hline AMOSTRAS & $\begin{array}{c}\text { AGREGADO } \\
(\mathrm{g})\end{array}$ & $\begin{array}{c}\text { AGLOMERANTE } \\
(\mathrm{g})\end{array}$ & AGREG/AGLO & $\begin{array}{c}\text { TRAÇO } \\
\text { EQUIVALENTE }\end{array}$ \\
\hline A1 & 86,2 & 13,8 & 6,25 & $1: 6$ \\
\hline A2 & 88,3 & 11,7 & 7,55 & $1: 7$ \\
\hline A3 & 87,8 & 12,2 & 7,20 & $1: 7$ \\
\hline A4 & 87,3 & 12,7 & 7,20 & $1: 7$ \\
\hline A5 & 87,8 & 12,2 & 6,46 & $1: 6$ \\
\hline A6 & 86,6 & 13,4 & 6,09 & $1: 6$ \\
\hline
\end{tabular}

Fonte: Autoria Própria (2018).

Por meio da referida tabela é possível observar que dentre as sete amostras analisadas foram obtidos dois tipos de traços, sendo eles 1:6 e 1:7. 
A variedade de traços poderia ser explicada em razão do uso em diferentes paredes, de ambientes externos ou internos. Entretanto, de acordo com o mapeamento realizado foi observado que um mesmo ambiente possui traços diferentes, como por exemplo, as paredes de na qual foram extraídas as amostras A1 e A2. Logo, a diferença entre os mesmos pode ser explicada em razão da não existência de controle tecnológico na produção da argamassa utilizada, na qual não era seguido um padrão em relação a proporção dos materiais utilizados e nem se era feito um mapeamento do uso da argamassa, fato mais uma vez demonstrado com o emprego do mesmo traço nas amostras A1 e A6, que correspondem a um ambiente interno e outro externo, respectivamente.

\subsection{Granulometria}

A Tabela 2 mostra os percentuais passantes de cada uma das amostras pela série de peneiras utilizadas no ensaio de granulometria. Pela referida tabela é possível observar que as amostras apresentam pouca diferenciação no que se diz respeito ao tamanho de seus grãos, o que indica que os materiais empregados na sua produção são similares.

Tabela 2 - Análise granulométrica através do material passante

\begin{tabular}{c|c|c|c|c|c|c|c}
\hline \multicolumn{1}{c|}{} & \multicolumn{1}{c}{ \% PASSANTE } \\
\hline ABERTURA & A1 & A2 & A3 & A4 & A5 & A6 & A7 \\
\hline $4,75 \mathrm{~mm}$ & 99,85 & 99,28 & 100 & 99,7 & 100 & 100 & 100 \\
\hline $2,36 \mathrm{~mm}$ & 85,74 & 74,17 & 83,27 & 85,6 & 90,45 & 89,82 & 85,24 \\
\hline $1,18 \mathrm{~mm}$ & 70,6 & 55,55 & 66,66 & 66,14 & 74,05 & 74,82 & 69,37 \\
\hline $0,600 \mathrm{~mm}$ & 43,43 & 33,27 & 40,13 & 41,53 & 48,2 & 52 & 46,06 \\
\hline $0,425 \mathrm{~mm}$ & 27,44 & 19,23 & 23,39 & 25,86 & 32,63 & 34,08 & 32,34 \\
\hline $0,250 \mathrm{~mm}$ & 9,54 & 6,67 & 7,97 & 8,76 & 14,7 & 13,31 & 11,6 \\
\hline $0,150 \mathrm{~mm}$ & 1,97 & 1,6 & 1,69 & 2,3 & 5,96 & 2,1 & 2 \\
\hline $0,075 \mathrm{~mm}$ & 0,38 & 0,34 & 0,29 & 0,46 & 1,6 & 0,24 & 0,29
\end{tabular}

Fonte: Autoria Própria (2018).

Na Figura 4 é apresentada a curva granulométrica obtida após o ensaio de granulometria. Por meio das curvas granulométricas da figura, é possível confirmar a similaridade na distribuição das partículas existentes nas amostras de argamassas estudadas, pois suas curvas apresentam um comportamento muito semelhante. O agregado miúdo analisado apresenta uma boa graduação, ou seja, desde grãos menores aos maiores. Uma boa graduação para areia se faz importante, pois faz com que ocorra certa acomodação entre as partículas, diminuindo assim o consumo de água em razão da diminuição dos vazios no material, essa água que posteriormente seria evaporada, acarretaria perdas de resistência, bem como o possível surgimento de fissuras devido a retração. 


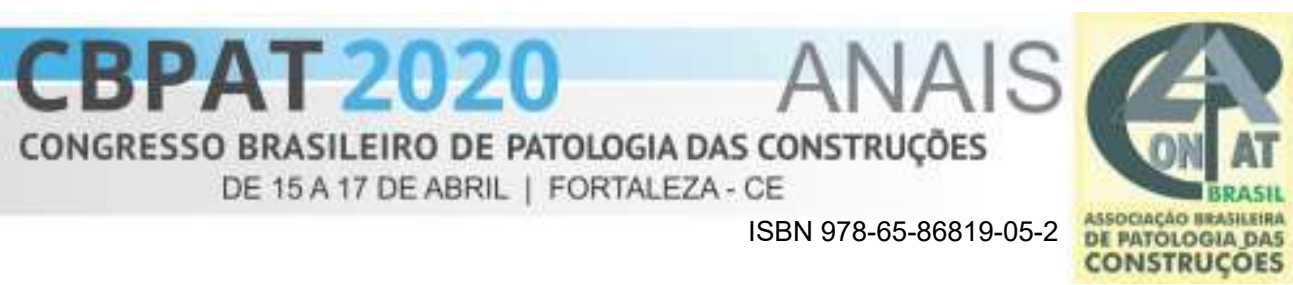

Figura 4 - Curva de distribuição granulométrica.

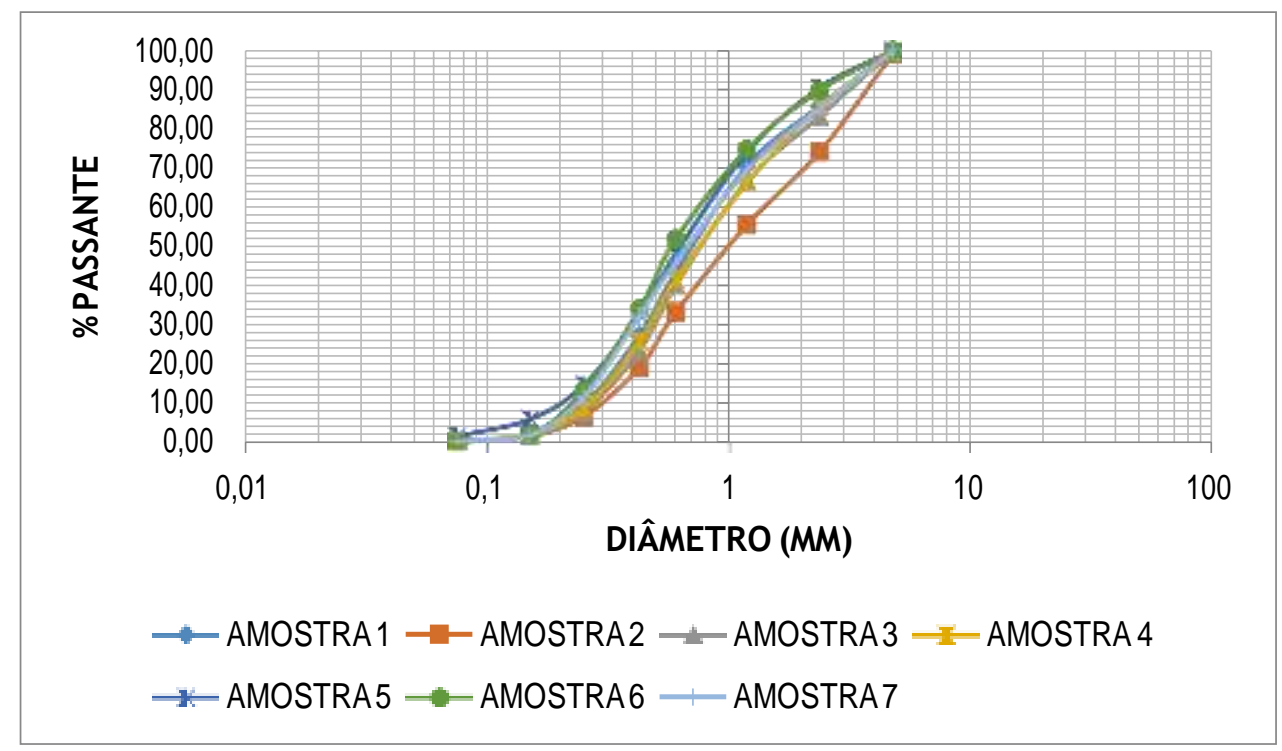

Fonte: Autoria Própria (2018).

O módulo de finura, bem como o diâmetro máximo dos grãos está representado na Tabela 3.

Tabela 3 - Módulo de finura e diâmetro máximo.

\begin{tabular}{c|c|c|c|c|c|c|c}
\hline & A 1 & A 2 & A 3 & A 4 & A 5 & A 6 & A 7 \\
\hline M.F. & 4,61 & 5,1 & 4,77 & 4,7 & 4,32 & 4,34 & 4,53 \\
\hline Dmáx (mm) & 4,75 & 4,75 & 4,75 & 4,75 & 4,75 & 4,75 & 4,75 \\
\hline
\end{tabular}

Fonte: Autoria Própria (2018).

De acordo com os valores de módulo de finura apresentados, pode-se observar que a areia empregada na fabricação da argamassa utilizada no revestimento da edificação se constitui de uma areia grossa, com modulo de finura bastante elevado. Ainda de acordo com o referido quadro é possível denotar certa similaridade entre os módulos de finuras, o que pressupõe que as areias podem ter sido extraídas da mesma jazida.

\subsection{Absorção}

Por meio dos resultados do ensaio de absorção apresentados na Figura 5, é possível observar a taxa média de absorção de água ao fim do ensaio realizado das amostras analisadas. 
Figura 5 - Taxa de absorção

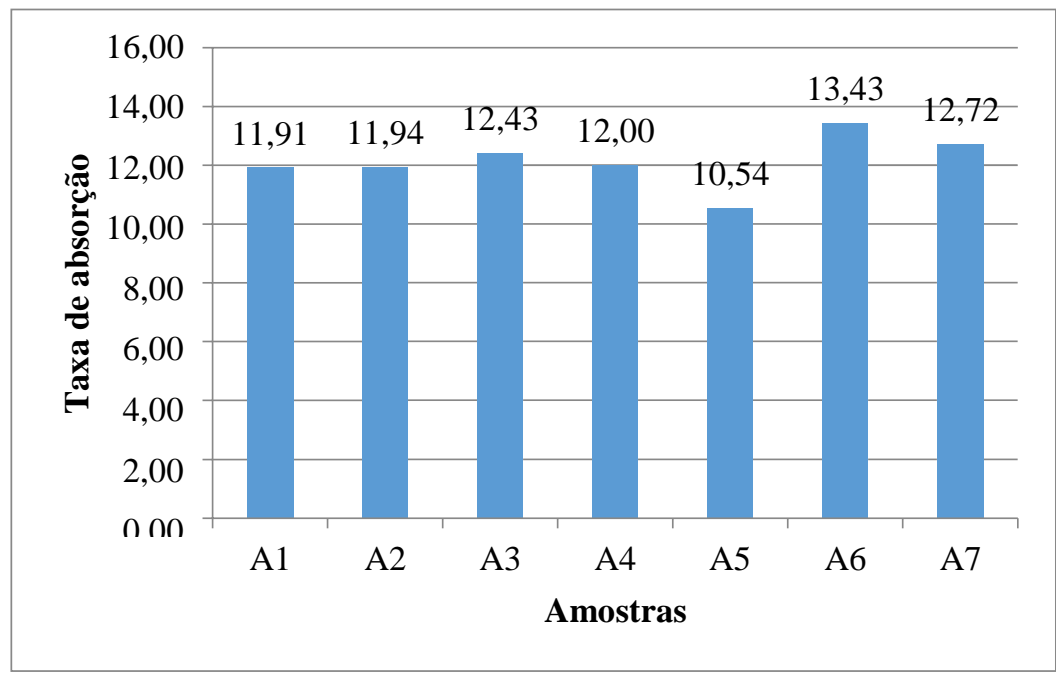

Fonte: Autoria Própria (2018).

A amostra identificada como A5 foi a que apresentou uma menor taxa de absorção, com valores em torno de $10 \%$, enquanto que a amostra representada como A6 demonstrou a maior taxa de absorção, com valores em torno de $12 \%$. O desvio padrão calculado foi de 0,82 . Em comparação com taxas de absorção em concretos, por exemplo, as taxas apresentadas pelas amostras apresentadas são aproximadamente 50\% maior. O que dá um indicativo de que realmente as argamassas de cal apresentam maior quantidade de poros que argamassas ou concretos com cimento.

\section{CONCLUSÃO}

O presente trabalho teve por objetivo realizar a caracterização de argamassas históricas presentes no revestimento do Mercado Público construído em 1951 na cidade de Jardim de Piranhas/RN. A partir das análises realizadas é possível fazer as seguintes considerações:

- $\quad$ Os traços encontrados foram os de 1:6 e 1:7;

- Há uma diversificação entre os traços identificados em um mesmo ambiente;

- Não há um padrão de alteração da proporção dos materiais usados em função da exposição ao qual a parede está sujeita (ambiente interno ou externo);

- A areia usada apresenta uma boa graduação e pode ser classificada como areia grossa;

- As argamassas apresentam taxas significativas de absorção, o que condiz com o elevado teor de areia em comparação ao teor do ligante usado e a ausência de material cimentício.

Por fim, é observada a importância da realização dos estudos relacionados às argamassas históricas, principalmente no que concerne a sua caracterização, já que isso significa não só a restauração de maneira correta de edificações antigas, mas, sobretudo a preservação da memória de uma cidade, região ou país.

\section{REFERÊNCIAS}

ABCP, 2002. MANUAL DE REVESTIMENTOS DE ARGAMASSA. 1. ed. São Paulo, SP, Associação Brasileira de Cimento Portland (ABCP). 
ALARCÃO, J. (1978). Argamassas na Antiguidade. In: «História», N², Lisboa, Prójornal: 20-24.

ALMEIDA, Luís Filipe dos Santos de. CARACTERIZAÇÃo DAS ARGAMASSAS DA MURALHA TARDO

- ROMANA DE OLISIPO. 2015. 194 f. Dissertação (Mestrado) -

Curso de Mestrado em Geologia Aplicada, Departamento de Geologia, Universidade de Lisboa, Lisboa - Portugal, 2015.

ASSOCIAÇÃO BRASILEIRA DE NORMAS TÉCNICAS. NBR 7175: Cal Hidratada Para

Argamassas - Requisitos. Rio de Janeiro: Abnt, 2003. 4 p.

ASSOCIAÇÃO BRASILEIRA DE NORMAS TÉCNICAS. NBR NM 248: - AGREGADOS

- DETERMINAÇÃO DA COMPOSIÇÃO GRANULOMÉTRICA. Rio de Janeiro: Abnt, 2003. 13 p.

ASSOCIAÇÃO BRASILEIRA DE NORMAS TÉCNICAS. NBR 9778: ARGAMASSA E CONCRETO ENDURECIDOS - DETERMINAÇÃO DA ABSORÇÃO DE ÁGUA ÍNDICE DE VAZIOS E MASSA ESPECÍFICA. Rio de Janeiro: Abnt, 2005. 8 p.

BOYTON, R. S. (2008). CHEMISTRY AND TECHNOLOGY OF LIME AND

LIMESTONE, $2^{a}$ edição, New York, Chichester, Brisbane, Toronto, John Wiley \& Sons, Inc., 1980.

BRASIL. Instituto do Patrimônio Histórico e Artístico Nacional. Ministério da Cidadania. O Iphan. 2019. Disponível em: http://portal.iphan.gov.br/pagina/detalhes/872. Acesso em: 21 fev. 2019.

CINCOTTO, M.a.; QUARCIONI, V.a.; JOHN, V.m. (Ed.). Cal na construção civil. In: GERALDO C. ISAIA (São Paulo). Instituto Brasileiro do Concreto (ibracon) (Ed.). Materiais de Construção Civil e Princípios de Ciência e Engenharia dos Materiais. São Paulo: Ibracon, 2010.

COUTINHO, A. S., 1997, “FABRICO E PROPRIEDADES DO BETÃO”. Volumes I e II, $3^{a}$ edição. LNEC. Lisboa.

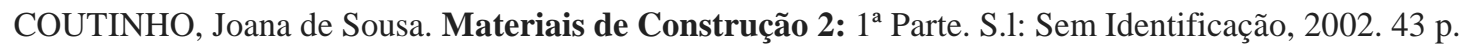

DAMAS, Ana Leonor Ortin Rodrigues. CARACTERIZAÇÃo DE ARGAMASSAS DE ASSENTAMENTO DE AZULEJO ANTIGAS: Contributo para a conservação deste tipo de revestimentos. 2017. 151 f. Dissertação (Mestrado) - Curso de Mestrado em Engenharia Civil, Universidade Nova de Lisboa, Lisboa - Portugal, 2017.

FARIA, P. (2004). ARGAMASSAS DE REVESTIMENTOS PARA ALVENARIAS ANTIGAS. CONTRIBUIÇÃO PARA O ESTUDO DA INFLUENCCIA DOS LIGANTES.

Tese de Doutorado em Engenharia Civil, FCT-UNL, Monte da Caparica.

GONÇALVES, T. D., Pel, L., Rodrigues, J. D. (2009). INFLUENCE OF PAINTS ON DRYING AND SALT DISTRIBUTION PROCESSES IN POROUS BUILDING

MATERIALS. Construction and Building Materials, 23:1751-1759. DOI: 10.1016/j.conbuildmat.2008.08.006.

GONÇALVES, T. D., Brito, V., Musacchi, J. (2014). THE WHOLE AND THE PARTS: CAN LIME COATINGS ENHANCE THE DRYING OF SALT LADEN MATERIALS.

Construction and Building Materials, 57:179-189, http://dx.doi.org/10.1016/j.conbuildmat.2014.02.007.

HENRIQUES, F. M. A. (1996). "Gesso". Apontamentos de Materiais de Construção. Departamento de Engenharia Civil, FCT-UNL, Monte da Caparica.

HUGHES, John J. THE ROLE OF MORTAR IN MASONRY: AN INTRODUCTION TO REQUIREMENTS FOR THE DESING OF REPAIR MORTARS. Materials and

Structures: RILEM TC 203-RHM: Repair mortars for historic masonry. Scotland, UK, p. 1287-1294, 2012. 
Instituto Brasileiro de Geografia e Estatística (2019). Disponível em: https://cidades.ibge.gov.br/brasil/rn/jardim-depiranhas/panorama. Acesso em: 24 fev. 2019. ISAIA Geraldo C (Ed.). Argamassas: Capítulo 26 - Argamassas. S.1: Ibracon, 2019. 79 p

KANAN, Maria Isabel. MANUAL DE CONSERVAÇÃO E INTERVENÇÃO EM ARGAMASSAS E REVESTIMENTOS À BASE DE CAL. Brasília, DF :. 172 p. Iphan /

Programa Monumenta, 2008.

MADALENA, Luís Miguel do Nascimento. Influência do teor em pozolana na reatividade e nas características mecânicas de argamassas. 2013. 101 f. Dissertação (Mestrado) - Curso de Pós-graduação em Engenharia Civil, Universidade Nova de Lisboa, Lisboa - Portugal, 2013.

Margalha, M. G. (2011). “Argamassas”. Documento de apoio às aulas de Conservação e Recuperação do Património. Évora: Universidade de Évora.

MOROPOULOU, A.; POLIKRETTI, K.; BAKOLAS, A.; MICHAILIDIS, P., 2003, “CORRELATION OF PHYSICOCHEMICAL AND MECHANICAL PROPERTIES OF HISTORICAL MORTARS AND CLASSIFICATION BY MULTIVARIATE

STATISTICS”. Cement \& Concrete Research 33, pp. 891 - 898.

NASCIMENTO, C. B. do. MÉTODO DE CARACTERIZAÇÃO DE ARGAMASSAS HISTÓRICAS: PROPOSIÇÃO E ESTUDOS DE CASO. In: CONGRESO IBEROAMERICANO Y VIII JORNADA "TÉCNICAS DE RESTAURACIÓN Y CONSERVACIÓN DEL PATRIMONIO”, 1., 2009, Buenos Aires,

Argentina. Artigo. Buenos Aires, Argentina: Congreso Iberoamericano y Viii Jornada "técnicas de Restauración y Conservación del Patrimonio", 2009. p. 1 - 10.

PAPAYIANNI, I., Stefanidou, M. (2007). DURABILITY ASPECTS OF ANCIENT

MORTARS OF THE ARCHEOLOGICAL. site of Olynthos. Journal of Cultural Heritage, 8(2):193-196. http://dx.doi.org/10.1016/j.culher.2007.03.001.

PAPAYIANNI, I., Pachta, V., Stefanidou, M. (2013). ANALYSIS OF ANCIENT MORTARS AND DESIGN OF COMPATIBLE REPAIR MORTARS: THE CASE

STUDY OF ODEION OF THE ARCHAELOGICAL. site of Dion. Construction and Building Materials, 40:84-92. http://dx.doi.org/10.1016/j.conbuildmat.2012.09.086.

PAIVA, S. C.; Gomes, E. A. O. e Oliveira, R. A., "Controle de qualidade da cal para argamassas - metodologias alternativas", Revista Ciências \& Tecnologia, vol. 1, pp. 1-11, julho-dezembro 2007.

RODRIGUES, Paula Nader. CARACTERIZAÇÃO DAS ARGAMASSAS HISTÓRICAS

DA RUÍNA DE SÃO MIGUEL ARCANJO/RS. 2013. 142 f. Dissertação (Mestrado) - Curso de Pós-graduação em Engenharia Civil, Universidade Federal de Santa Maria, Santa Maria/rs, 2013.

ROSA, Paulo Jorge Pereira da. Caracterização de Argamassas Históricas do Convento de Cristo - Tomar. 2016. 216 f. Dissertação (Mestrado) - Curso de Mestrado em Química, Universidade de Lisboa, Lisboa - Portugal, 2016.

SANTOS, Ana Rita; VEIGA, Maria do Rosário. ARGAMASSAS COMPATÍVEIS PARA

EDIFÍCIOS ANTIGOS. In: LNEC, 2012, Lisboa - Portugal. Artigo. Lisboa: Lnec, 2012. p. 1 -11 .

SOUSA, Adla Kellen Dionisio. Argamassas do Grupo Escolar Augusto Severo/RN: Caracterização e Incidência de Manifestações Patológicas. 2014. 142 f. Dissertação (Mestrado) - Curso de Pós-graduação em Engenharia Civil, Departamento de Geologia, Universidade Federal do Rio Grande do Norte, Natal/RN, 2014.

VEIGA, M. R., Aguiar, J., SANTOS, Silva. A., CARVALHO, F. METHODOLOGIES FOR CHARACTERISATION AND REPAIR OF MORTARS OF ANCIENT

BUILDINGS. Proceedings of the $3^{\text {rd }}$ International Seminar on Historical Constructions, Guimarães, 2001, $353-362$. 


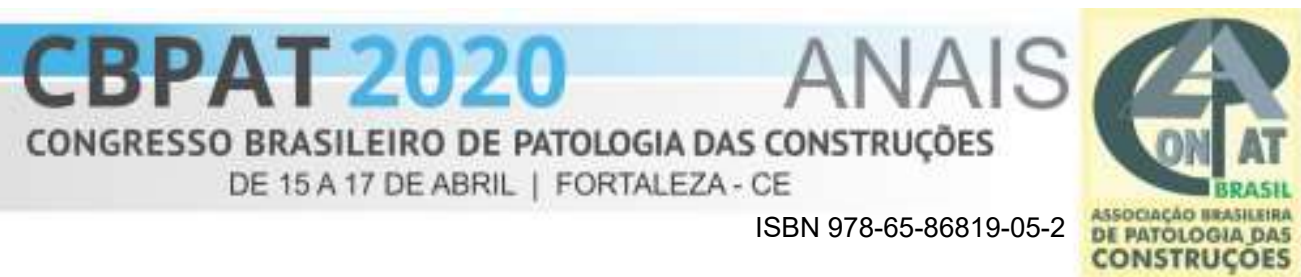

VEIGA, M. R. (2003). ARGAMASSAS PARA REVESTIMENTO DE PAREDES DE

EDIFÍCIOS ANTIGOS. Características e campo de aplicação de algumas formulaçõescorrentes. In: $3^{\circ} \mathrm{ENCORE,}$ Encontro sobre Conservação e Reabilitação de Edifícios. Lisboa, LNEC.

Veiga, M. R. (2006a). Os revestimentos antigos e a identidade dos edifícios. Arquitectura Ibérica, Reabilitação, $\mathrm{n}^{\circ} 12$.

Veiga, M. R. (2006b). Intervenções em revestimentos antigos: conservar, substituir ou...destruir. In: $2^{\circ}$ Encontro sobre Patologia e Reabilitação de edifícios (PATORREB), Porto. 